\title{
Karawitan di Wilayah Terban, Gondokusuman, Yogyakarta
}

Sutrisni

Jurusan Karawitan, Fakultas Seni Pertunjukan

Institut Seni Indonesia Yogyakarta Jalan Parangtritis Km 6,5, Sewon, Bantul, Daerah Istimewa Yogyakarta 55188 No.Hp.: ${ }^{1}+6287839345945$, E-mail: trisnisuborini@gmail.com 


\title{
Karawitan di Wilayah Terban, Gondokusuman, Yogyakarta
}

\author{
Sutrisni \\ Jurusan Karawitan, Fakultas Seni Pertunjukan \\ Institut Seni Indonesia Yogyakarta \\ Jalan Parangtritis Km 6,5, Sewon, Bantul, Daerah Istimewa Yogyakarta 55188 \\ No.Hp.: ${ }^{1}+6287839345945$, E-mail: trisnisuborini@gmail.com
}

\begin{abstract}
Abstrak
Kelurahan Terban, Gondokusuman, Yogyakarta selain mempertahankan upacara adat, juga konsisten untuk melestarikan kesenian tradisi Jawa, antara lain seni karawitan, seni tari, wayang kulit, dan teater/wayang wong. Belajar karawitan tidak bisa dilakukan secara instan, tetapi melalui proses yang panjang untuk bisa memahami, menguasai teknik, menghayati, kemudian merasakan. Hal ini yang belum dimiliki oleh ibu-ibu grup karawitan "Purba Laras". Oleh karena itu, ibu-ibu masih berkeinginan untuk memperdalam baik teknik menabuh maupun unggah-ungguh dalam menabuh gamelan. Untuk memperdalam penguasaan teknik menabuh gamelan dan unggah-ungguh dalam penyajian karawitan tersebut, dengan disertai semangat yang tinggi, grup "Purba Laras" bekerja sama dengan LPM Institut Seni Indonesia Yogyakarta. Metode yang digunakan adalah ceramah dan demonstrasi. Setelah mengikuti penyuluhan ibu-ibu mengerti unggah-ungguh, etika menabuh, juga konsep-konsep teknik tabuhan gaya Yogyakarta sehingga ikut serta memeriahkan upacara adat Rejeban dan Festival Karawitan.
\end{abstract}

Kata kunci: karawitan, grup "Purba Laras”, Kelurahan Terban

\section{Karawitan in Terban Area, Gondokusuman, Yogyakarta} Abstract

Terban sub-district, Gondokusuman, Yogyakarta, aside from conserving the traditional ceremony but also consistent in performing Javanese traditional arts, which are karawitan, dance, shadow puppets (wayang), and theater/wayang wong. Learning karawitan (how to play Javanese instrument) cannot be done in an instant as they have to go through a lengthy process to understand, master the technique, embody, and feel it. These are the things that the mothers within the "Purba Laras" karawitan group have not yet possess. Hence, the members are keen to learn further the mastery and the etiquette in playing gamelan. To deepen the gamelan technique and the etiquette in performing karawitan, accompanied with the high enthusiasm, "Purba Laras" group collaborates with LPM ISI Yogyakarta. The methods used are lecture and demonstration. After going through the counseling, the members understand well the "unggah-ungguh" (etiquette), the ethics in playing gamelan, and also the concepts of Yogyakarta gamelan play style, to the point that they are able to enliven the Rejeban traditional ceremony and Karawitan Festival.

Keyword: karawitan, "Purba Laras" Group, Terban Sub-district 


\section{PENDAHULUAN}

Terban adalah nama sebuah wilayah setingkat kelurahan yang berada di Kecamatan Gondokusuman, Daerah Istimewa Yogyakarta, dengan kode pos 55223. Kota ini berada sekitar $12 \mathrm{~km}$ ke arah utara dari kampus Institut Seni Indonesia Yogyakarta. Kantor Kelurahan Terban berada di Jalan Cik Ditiro, Terban, Yogyakarta. Masyarakat Terban walaupun berada di tengah kota yang begitu padat dan ramai, penduduknya masih menjunjung tinggi kebudayaan Jawa. Hal ini terbukti bahwa di kelurahan ini masih mengadakan perayaan upacara Rejeban dan upacara Bersih Belik. Upacara Rejeban dimaksudkan untuk mengirim doa tabur bunga kepada para leluhur. Upacara ini diadakan pada 31 Maret 2019, sedang upacara Bersih Belik diadakan pada Oktober, atau pada saat musim kemarau dan sumber air sudah mengering. Oleh karena itu, upacara Bersih Belik dimaksudkan untuk memohon keberkahan kepada Tuhan agar diberikan air yang melimpah.

Kelurahan Terban selain mempertahankan upacara adat, juga konsisten untuk melestarikan kesenian tradisi Jawa, antara lain seni karawitan, seni tari, wayang kulit, dan teater/wayang wong. Pemain wayang wong terdiri atas ibu-ibu penduduk Sagan, Kelurahan Terban dan sekitarnya. Namun, pada lima tahun terakhir, kegiatan wayang wong telah vakum. Kemudian untuk mengisi kegiatan yang vakum tersebut, para pemainnya termasuk ibu-ibu beralih belajar karawitan.

Karawitan di wilayah Terban ini terdiri atas beberapa grup, antara lain grup bapak-bapak, yaitu para pengrawit yang sudah mumpuni (profesional) yang mengadakan latihan setiap satu bulan sekali (selapanan) pada setiap Jumat Legi malam, dan grup ibu-ibu dengan nama "Purba Laras". Grup Karawitan "Purba Laras" berdiri sejak tahun 2015, diketuai oleh Drs. Bambang Purnomo, S.E.,
M.Si. Anggota karawitan "Purbo Laras" terdiri atas ibu-ibu rumah tangga di sekitar wilayah Kelurahan Terban. Latar belakang ibu-ibu dalam belajar karawitan didasari oleh kesenangan atau hobi terhadap seni karawitan. Pelatihan karawitan ibu-ibu "Purba Laras" didukung dan difasilitasi dengan seperangkat gamelan perunggu berlaraskan slendro dan pelog milik Bambang Purnomo selaku ketua karawitan. Gamelan merupakan napas bagi para seniman karawitan (Fatimah, 2019:1). Grup karawitan "Purba Laras" diasuh oleh Bapak Heri, yaitu seniman karawitan awam. Grup ini mengadakan latihan setiap Minggu malam. Selama kurun waktu empat tahun, ibuibu dalam grup ini telah mendapatkan materi gending bentuk lancaran, gangsaran, ketawang, dan ladrang.

Belajar karawitan tidak bisa dilakukan secara instan, tetapi melalui proses yang panjang untuk bisa memahami, menguasai teknik, menghayati, kemudian merasakan. Hal ini yang belum dimiliki oleh ibu-ibu secara umum. Oleh karena itu, ibu-ibu masih berkeinginan untuk memperdalam baik teknik menabuh maupun unggah-ungguh dalam menabuh gamelan. Untuk memperdalam penguasaan teknik menabuh gamelan dan unggah-ungguh dalam penyajian karawitan tersebut, dengan disertai semangat yang tinggi, grup "Purba Laras" bekerja sama dengan LPM Institut Seni Indonesia Yogyakarta.

Berdasarkan latar belakang potensi yang dimiliki dan kebutuhan ibu-ibu tersebut, pelatihan untuk menambah wawasan, keilmuan teknik menabuh, unggah-ungguh dalam penyajian karawitan sangat diperlukan. Hal tersebut berhubungan dengan adanya pementasan untuk Rejeban, 31 Maret 2019 dan untuk mengikuti Festival Karawitan Putri, 25 April 2019 yang sifatnya sangat mendadak. Pelatihan karawitan dan pelatihan sinden diharapkan memiliki beberapa tujuan. Peserta pelatihan diharapkan dapat mengerti teknik- 
teknik dasar tabuhan gamelan, baik pada instrumen bentuk pencon maupun bentuk bilah, khususnya teknik tabuhan gaya Yogyakarta, dalam bentuk lancaran, ladrang, dan playon sesuai dengan ricikan yang disajikan. Peserta juga akan mampu memahami unggah-ungguh menabuh gamelan, unggah-ungguh sikap dalam menyajikan garap vokal, baik vokal gerongan maupun vokal sindenan.

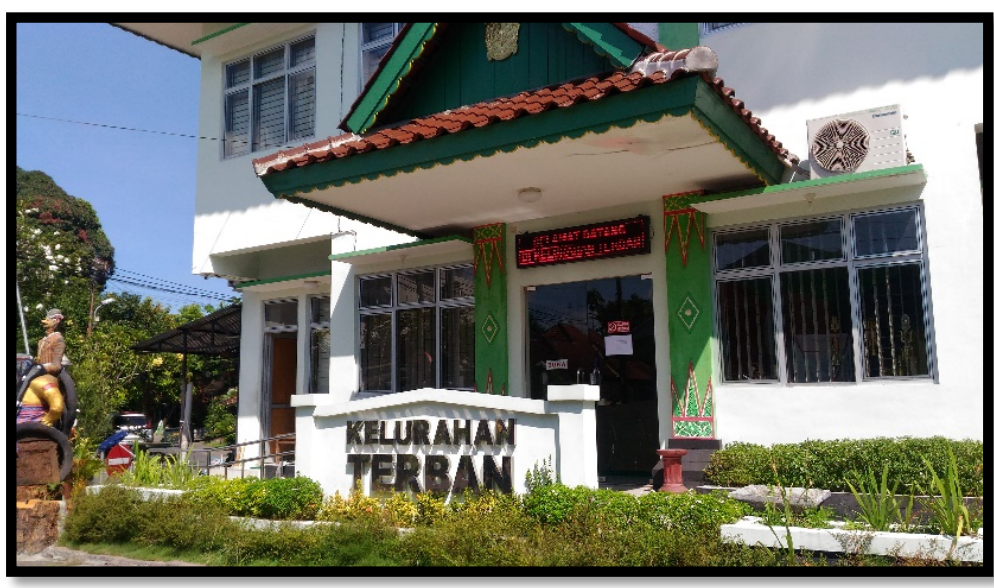

Gambar 1 Kantor Kelurahan Terban

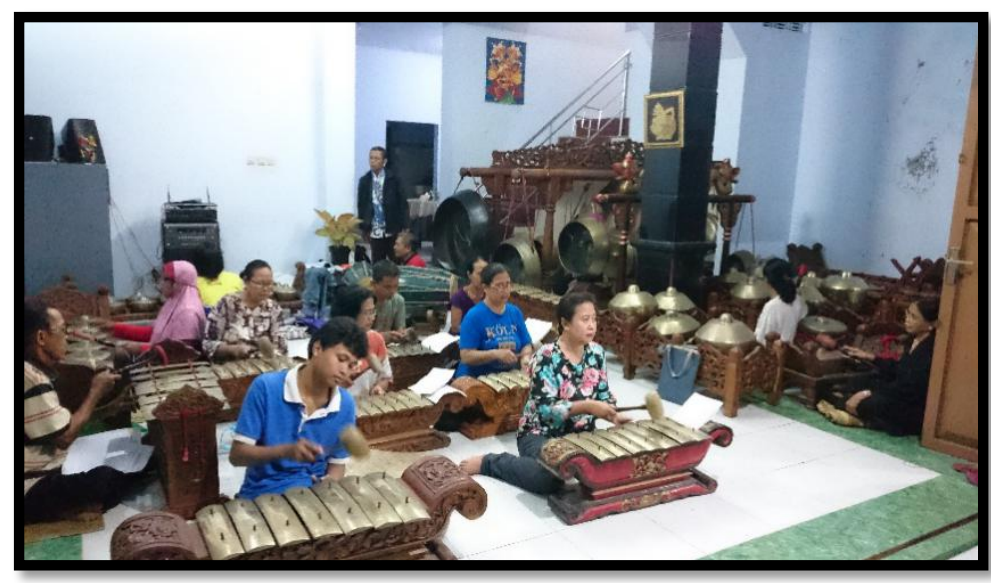

Gambar 2 Kegiatan Latihan

\section{METODE PENGABDIAN}

Pembelajaran karawitan selain mempelajari pengetahuan, etika, dan sikap unggah-ungguh dalam memainkan karawitan, juga memprioritaskan pembelajaran skill cara menabuh yang benar. Oleh karena itu, dalam pembelajaran penyuluh menggunakan metode yang tepat sesuai dengan kebutuhan tersebut. Agar peserta pembelajar jelas dan paham untuk menerima pembelajaran tersebut, digunakan metode antara lain:

a. Metode Ceramah

Metode ceramah adalah metode memberikan uraian atau penjelasan kepada sejumlah murid pada waktu dan tempat tertentu. Metode ceramah digunakan untuk menerangkan unggah-ungguh, etika dalam menabuh, dan garap karawitan yang 
berupa konsep. Menurut Chotimah (2019:4), unggah-ungguh adalah sebutan lain untuk budaya sopan santun dalam bahasa Jawa.

\section{b. Metode Demonstrasi}

Metode demonstrasi adalah cara penyajian pelajaran dengan memperagakan atau mempertunjukkan kepada peserta didik suatu proses, situasi, atau benda tertentu yang sedang dipelajari baik dalam bentuk sebenarnya ataupun dalam bentuk tiruan yang dipertunjukkan oleh guru atau sumber belajar lain yang ahli dalam topik bahasan (Bhidju, 2020:13). Metode demontrasi dipakai untuk memberikan contoh berupa teknik tabuhan seperti teknik necek pada tabuhan demung, saron dan peking, juga memberikan contoh olah vokal jineman, gerongan, dan sindenan.

\section{c. Metode Pelaksanaan}

Metode pelaksanaan pelatihan meliputi beberapa langkah pelaksanaan.

Tabel 1 Langkah Pelaksanaan Pelatihan Karawitan

\begin{tabular}{|c|c|c|c|c|}
\hline $\begin{array}{l}\text { Tatap } \\
\text { muka } \\
\text { ke- }\end{array}$ & $\begin{array}{c}\text { Waktu } \\
\text { Hari/jam }\end{array}$ & Materi & Tempat & Keterangan \\
\hline 1 & $\begin{array}{l}\text { Minggu } \\
24-03-2019 \\
\text { Pukul 19.00- } \\
22.00\end{array}$ & $\begin{array}{l}\text { Perkenalan } \\
\text { - Memperkenalkan diri } \\
\text { kepada peserta sebagai } \\
\text { utusan Jurusan } \\
\text { Karawitan, Fakultas } \\
\text { Seni Pertunjukan, ISI } \\
\text { Yogyakarta } \\
\text { - Mengenalkan simbol } \\
\text { penotasian } \\
\text { - Latihan gending- } \\
\text { gending } \\
\text { 1. Ldr. Sigramangsah } \\
\text { Pl. Barang } \\
\text { 2. Lac. Manyarsewu Pl } \\
\text { Nem } \\
\text { 3. Ldr. Asmadana Pl. } \\
\text { Nem. }\end{array}$ & $\begin{array}{l}\text { Sagan Gk } \\
\text { V/1112 RT } 45 \\
\text { RW 10, Terban, } \\
\text { Gondokusuman }\end{array}$ & $\begin{array}{l}\text { Latihan } \\
\text { persiapan } \\
\text { Rejeban }\end{array}$ \\
\hline 2. & $\begin{array}{l}\text { Kamis } \\
28-03-2019 \\
\text { Pukul 19.00- } \\
22.00\end{array}$ & $\begin{array}{l}\text { - Ldr Sigramangsah Pl. } \\
\text { Barang } \\
\text { - Lac. Manyarsewu Pl } \\
\text { Nem } \\
\text { - Ldr. Asmadana Pl. } \\
\text { Nem. } \\
\text { - Gending iringan tari } \\
\text { Golek Ayun-Ayun dan } \\
\text { tari menak Umarmaya- } \\
\text { Umarmadi }\end{array}$ & $\begin{array}{l}\text { Sagan Gk } \\
\text { V/1112 RT } 45 \\
\text { RW 10, Terban, } \\
\text { Gondokusuman }\end{array}$ & $\begin{array}{l}\text { Latihan } \\
\text { persiapan } \\
\text { Rejeban }\end{array}$ \\
\hline
\end{tabular}




\begin{tabular}{|c|c|c|c|c|}
\hline 3. & $\begin{array}{l}\text { Sabtu } \\
29-03.2019 \\
\text { Pukul 19.00- } \\
23.00\end{array}$ & $\begin{array}{l}\text { Manguyu-uyu: } \\
\text { - Ldr. Sigramangsah Pl. } \\
\text { Barang } \\
\text { - Lac. Manyarsewu Pl } \\
\text { Nem } \\
\text { - Ldr. Asmadana Pl. } \\
\text { Nem. } \\
\text { - Iringan Tari Golek } \\
\text { Ayun-Ayun dan tari } \\
\text { menak Umarmaya- } \\
\text { Umarmadi. }\end{array}$ & $\begin{array}{l}\text { Sagan Gk } \\
\text { V/1112 RT } 45 \\
\text { RW 10,Terban, } \\
\text { Gondokusuman }\end{array}$ & $\begin{array}{l}\text { Latihan } \\
\text { persiapan } \\
\text { Rejeban }\end{array}$ \\
\hline 4 & $\begin{array}{l}\text { Minggu } \\
31-03-2019 \\
\text { Pukul 19.00- } \\
24.00\end{array}$ & $\begin{array}{l}\text { Untuk praacara: } \\
\text { - Ldr. Kenceng Pl Nem } \\
\text { - Lac. Manyarsewu Pl } \\
\text { Nem } \\
\text { - Ldr. Asmadana Pl. } \\
\text { Nem. } \\
\text { Untuk iringan Tari } \\
\text { - Golek Ayun-Ayun dan } \\
\text { tari menak Umarmaya- } \\
\text { Umarmadi. }\end{array}$ & $\begin{array}{l}\text { Sagan Gk } \\
\text { V/1112 RT } 45 \\
\text { RW 10, Terban, } \\
\text { Gondokusuman } \\
\text { Terban }\end{array}$ & $\begin{array}{l}\text { Pentas } \\
\text { Rejeban }\end{array}$ \\
\hline 5 & $\begin{array}{l}\text { Minggu } \\
\text { 07-04-2019 } \\
\text { Pukul 19.00- } \\
22.00\end{array}$ & $\begin{array}{l}\text { Ldr. Wani-Wani Laras } \\
\text { Slendro Patet Manyura } \\
\text { Garap Soran }\end{array}$ & $\begin{array}{l}\text { Sagan Gk } \\
\text { V/1112 RT } 45 \\
\text { RW 10,Terban, } \\
\text { Gondokusuman }\end{array}$ & $\begin{array}{l}\text { Latihan } \\
\text { persiapan } \\
\text { Festival } \\
\text { Karawitan } \\
\text { Putri }\end{array}$ \\
\hline 6 & $\begin{array}{l}\text { Jumat } \\
12-4-2019 \\
\text { Pukul 15- } \\
18.00\end{array}$ & $\begin{array}{l}\text { Ldr. Wani-Wani Laras } \\
\text { Slendro Patet Manyura } \\
\text { Garap Soran } \\
\text { - Jineman Patanya, } \\
\text { - Gending Sri Kaloka, } \\
\text { Lac. Nyata Kowe Wasis } \\
\text { Lrs, Pl Patet Barang }\end{array}$ & $\begin{array}{l}\text { Sagan Gk } \\
\text { V/1112 RT } 45 \\
\text { RW 10,Terban, } \\
\text { Gondokusuman }\end{array}$ & $\begin{array}{l}\text { Latihan } \\
\text { persiapan } \\
\text { Festival } \\
\text { Karawitan } \\
\text { Putri }\end{array}$ \\
\hline 7 & $\begin{array}{l}\text { Sabtu } \\
13-4-2019\end{array}$ & $\begin{array}{l}\text { - Ldr. Wani-Wani } \\
\text { Laras Slendro Patet } \\
\text { Manyura Garap Soran }\end{array}$ & $\begin{array}{l}\text { Sagan Gk } \\
\text { V/1112 RT } 45\end{array}$ & $\begin{array}{l}\text { Latihan } \\
\text { persiapan } \\
\text { Festival }\end{array}$ \\
\hline
\end{tabular}




\begin{tabular}{|c|c|c|c|c|}
\hline & $\begin{array}{l}\text { Pukul 15.00- } \\
18.00\end{array}$ & $\begin{array}{l}\text { - ineman Patanya, } \\
\text { - Gending Sri Kaloka, } \\
\text { - Lac. Nyata Kowe } \\
\text { Wasis Lrs, Pl Patet } \\
\text { Barang }\end{array}$ & $\begin{array}{l}\text { RW 10,Terban, } \\
\text { Gondokusuman }\end{array}$ & $\begin{array}{l}\text { Karawitan } \\
\text { Putri }\end{array}$ \\
\hline 8 & $\begin{array}{l}\text { Minggu } \\
\text { 14-04-2019 } \\
\text { Pukul 19.00- } \\
\text { 22-00 }\end{array}$ & $\begin{array}{l}\text { - Ldr. Wani-Wani } \\
\text { Laras Slendro Patet } \\
\text { Manyura Garap Soran } \\
\text { - Jineman Patanya, } \\
\text { - Gending Sri Kaloka, } \\
\text { - Lac. Nyata Kowe } \\
\text { Wasis Lrs, Pl Patet } \\
\text { Barang }\end{array}$ & $\begin{array}{l}\text { Sagan Gk } \\
\text { V/1112 RT } 45 \\
\text { RW 10,Terban, } \\
\text { Gondokusuman }\end{array}$ & $\begin{array}{l}\text { Latihan } \\
\text { persiapan } \\
\text { Festival } \\
\text { Karawitan } \\
\text { Putri }\end{array}$ \\
\hline 9. & $\begin{array}{l}\text { Minggu } \\
21-04-2019 \\
\text { Pukul 19.00- } \\
22.00\end{array}$ & $\begin{array}{l}\text { Ldr. Wani-Wani Laras } \\
\text { Slendro Patet Manyura } \\
\text { Garap Soran } \\
\text { - Jineman Patanya, } \\
\text { - Ldr. Sri Kaloka, } \\
\text { - Lac. Nyata Kowe } \\
\text { Wasis Lrs, Pl Patet } \\
\text { Barang }\end{array}$ & $\begin{array}{l}\text { Terban Gk } \\
\text { V/1112 RT } 45 \\
\text { RW 10,Terban, } \\
\text { Gondokusuman }\end{array}$ & $\begin{array}{l}\text { Latihan } \\
\text { persiapan } \\
\text { Festival } \\
\text { Karawitan } \\
\text { Putri }\end{array}$ \\
\hline 10. & $\begin{array}{l}\text { Rabu } \\
24-04-2019 \\
\text { Pukul 17.00- } \\
19.00\end{array}$ & $\begin{array}{l}\text { - Ldr. Wani-Wani } \\
\text { Laras Slendro Patet } \\
\text { Manyura Garap Soran } \\
\text { - Jineman Patanya, } \\
\text { - Ldr. Sri Kaloka, } \\
\text { - Lac. Nyata Kowe } \\
\text { Wasis Lrs, Pl Patet } \\
\text { Barang }\end{array}$ & $\begin{array}{l}\text { Dalem } \\
\text { Mangkubumen }\end{array}$ & $\begin{array}{l}\text { GR.Festival } \\
\text { Karawitan } \\
\text { Putri }\end{array}$ \\
\hline 11 & $\begin{array}{l}\text { Minggu } \\
25-04-2019 \\
\text { Pukul 12.00- } \\
18.00\end{array}$ & $\begin{array}{l}\text { Ldr. Wani-Wani Laras } \\
\text { Slendro Patet Manyura } \\
\text { Garap Soran } \\
\text { - Jineman Patanya, } \\
\text { - Ldr. Sri Kaloka, } \\
\text { - Lac. Nyata Kowe } \\
\text { Wasis Lrs, Pl Patet } \\
\text { Barang }\end{array}$ & $\begin{array}{l}\text { Dalem } \\
\text { Mangkubumen }\end{array}$ & $\begin{array}{l}\text { Festival } \\
\text { Karawitan } \\
\text { Putri }\end{array}$ \\
\hline
\end{tabular}




\begin{tabular}{l|l|l|l|l}
\hline 12 & Minggu & - Gending iringan & Sagan Gk & Latihan \\
& 02-05-2019 & Senam Pagi & V/1112 RT 45 & terakhir \\
& Pukul 19.00- & & RW 10,Terban, & \\
& 22.00 & & Gondokusuman & \\
& & & & \\
\hline
\end{tabular}

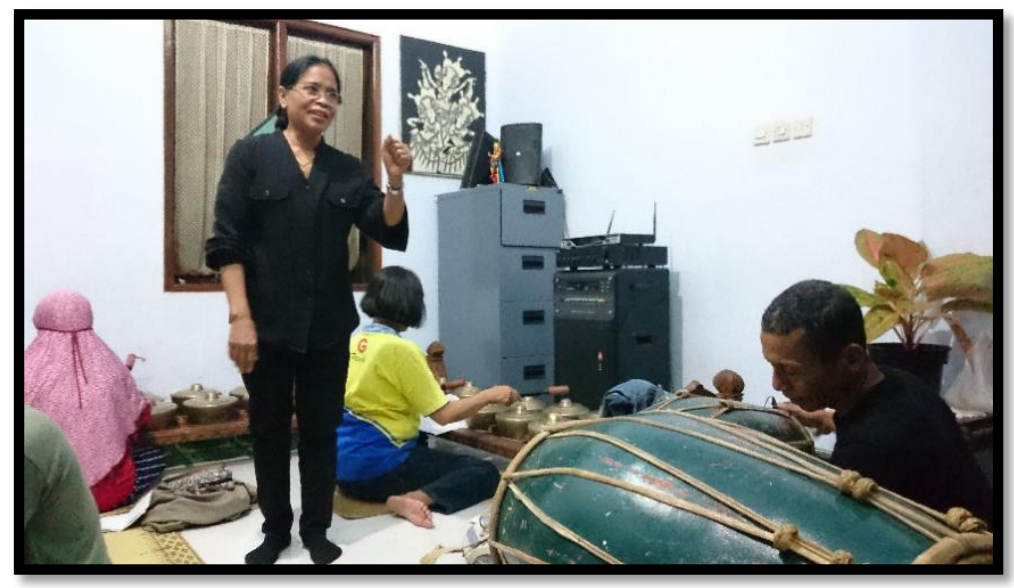

Gambar 3 Kegiatan Latihan

\section{HASIL DAN PEMBAHASAN}

Hasil pelatihan ini dapat dilihat dari bertambahnya pengetahuan ibu-ibu berkaitan dengan kegiatan karawitan. Setelah mengikuti penyuluhan, ibu-ibu memahami unggahungguh, etika menabuh, dan konsep-konsep teknik tabuhan gaya Yogyakarta. Secara teoretis, setelah mengerti konsep-konsep tersebut peserta juga dapat mendemonstrasikan teknik tabuhan necek untuk tabuhan saron, dan demung serta memahami untuk tabuhan peking teknik ndisiki, teknik tabuhan bonang gembyang minjal dan gembyang midak gaya Yogyakarta.

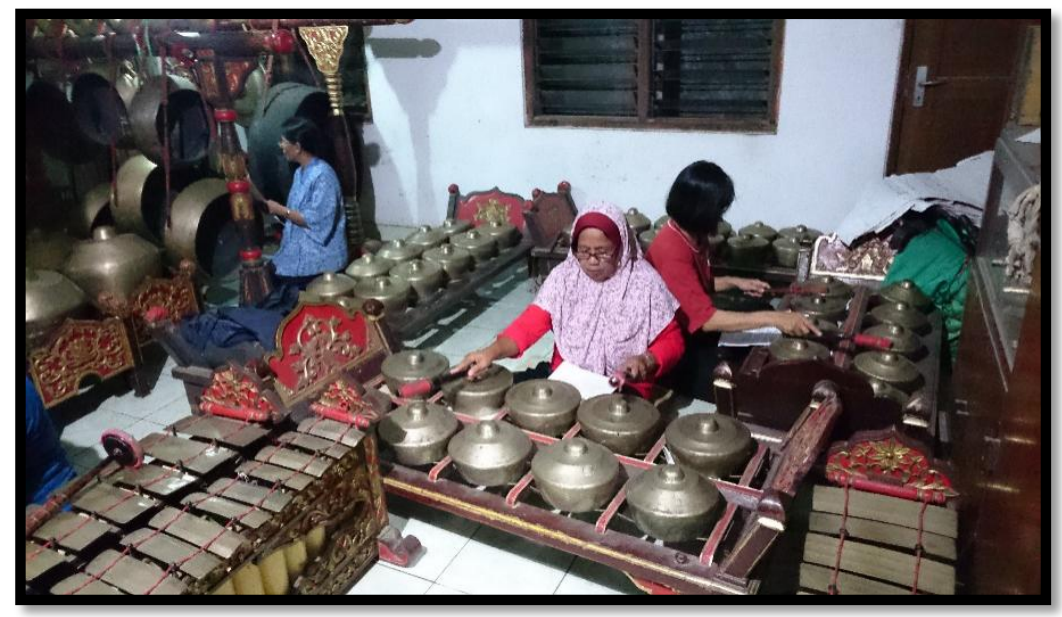

Gambar 4 Latihan Persiapan Festival Karawitan 


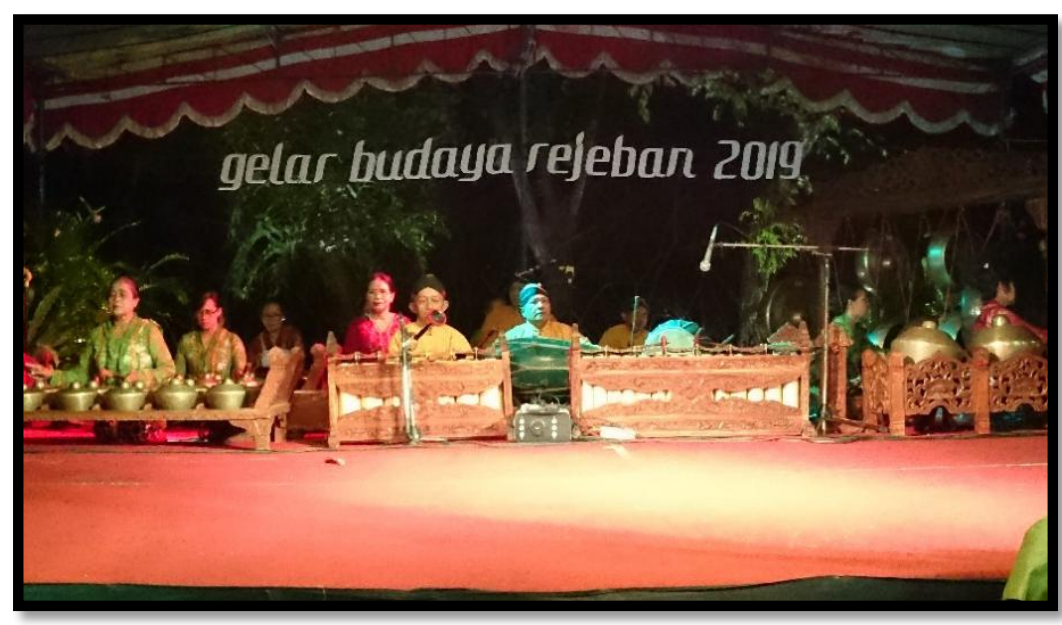

Gambar 5 Pementasan Gelar Budaya Rejeban

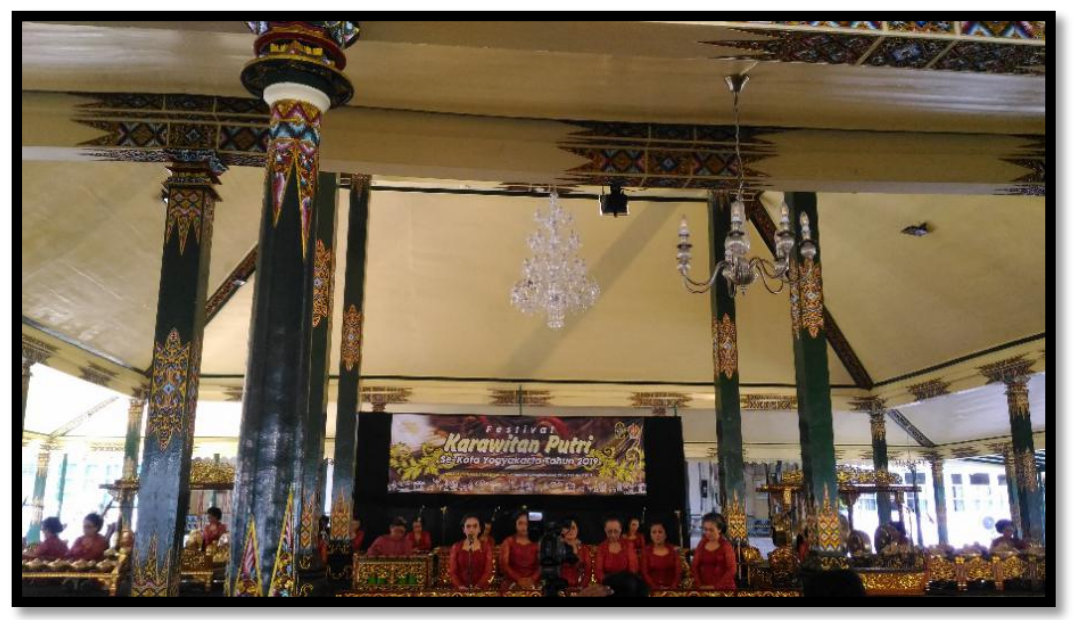

Gambar 6 Pementasan Festival Karawitan Putri

Kecamatan Gondokusuman

\section{SIMPULAN}

Penyuluhan karawitan di Sagan, Terban, Gondokusuman, Kota Yogyakarta selama satu bulan telah berjalan lancar sesuai dengan tujuan. Peserta suluh cepat memahami dan mengerti dengan materi yang penyuluh berikan. Dari akhir kegiatan ini, penyuluh berharap semoga penyuluhan ini bermanfaat bagi para peserta. Selanjutnya dengan program ini, semoga tetap terjalin rasa persaudaraan, tali silaturahmi sehingga tetap ada kesinambungan untuk program/rencana dalam pengembangan seni selanjutnya.

\section{SARAN}

Penulis berharap, suatu saat grup "Purba Laras" dan beberapa kesenian di Kelurahan Terban, Gondokusuman, Yogyakarta dapat dibantu dengan program Pembinaan Wilayah Seni ISI Yogyakarta.

\section{UCAPAN TERIMA KASIH}

Puji syukur ke hadirat Allah SWT atas rahmat-Nya yang telah memberikan kekuatan kepada penulis untuk menyelesaikan jurnal pengabdian masyarakat yang dilaksanakan di grup "Purba Laras” Terban, Gondokusuman, Yogyakarta. Ucapan terima kasih penulis 
sampaikan kepada LPM ISI Yogyakarta dan semua pihak yang telah membantu memperlancar dalam pelaksanaan kegiatan hingga terselesaikannya jurnal ini.

\section{DAFTAR PUSTAKA}

Bhidju, Roni Hariyanto. (201). Peningkatan Hasil Belajar IPA Metode Demonstrasi. Malang: Multimedia Edukasi.

Chotimah, Chusnul, Mei Fita Asri Untari, M. Arief Budiman. (2019). “Analisis
Penerapan Unggah Ungguh Bahasa Jawa dalam Nilai Sopan Santun", International Journal of Elementary School, Vol. 3 No. 2, Jurusan Pendidikan Guru SD, Universitas PGRI Semarang Indonesia.

Fatimah, Mutiara Dewi. (2019). "Eksistensi Karawitan Putri di Kota Budaya”, Acintya Jurnal Penelitian Seni Budaya, Vol. 11 No. 2, Prodi Etnomusikologi Fakultas Seni Pertunjukan ISI Surakarta. 